\title{
The perioperative nutritional care of neonates and infants
}

\author{
By Staffan Meurling
}

\begin{abstract}
The perioperative care of neonates and infants presents problems that differ greatly from those seen in older children and adults and has resulted, during the last few decades, in dramatically decreased morbidity and mortality rates in neonates and infants affected by congenital gastrointestinal malformations. Surgery-associated mortality in the neonate has declined from greater than $50 \%$ to less than $10 \%$. Refined respiratory care, antibiotics and improved nutrition with a greater knowledge of the needs of the surgical patient have together improved the survival chances for surgical neonates and infants. This article reviews some important aspects of the perioperative care of the neonate and infant.
\end{abstract}

Keywords: neonates, nutrition, postoperative care, surgery

\section{Introduction}

Advances in the perioperative care have dramatically decreased the morbidity and mortality rate in paediatric patients and especially among neonates affected by congenital gastrointestinal malformations (1).

Refined respiratory care, antibiotics and improved nutrition with a greater knowledge of the needs of the surgical patients have together ameliorated the chances for surgical neonates and infants (2). The nutritional requirements of adolescents and adults do not differ very much, so this review article will discuss the important factors for neonates and infants only in the perioperative period.

\section{Energy reserves}

Neonates have a high metabolic requirement and a small, limited nutritional reserve, particularly in the low birth weight (LBW) infant (3).

The total body water (TBW) declines from $85-90 \%$ in gestational weeks $25-28$ to $70-75 \%$ at term (4). In the first week of postnatal life TBW decreases by another $5 \%$ which is mainly noted by weight loss.

Staffan Meurling, MD, PhD, Director Neonatal Surgery, Children's Hospital University Hospital of Uppsala, SE-751 85 Uppsala, Sweden.

E.mail: staffan.meurling@kirurgi.uu.se

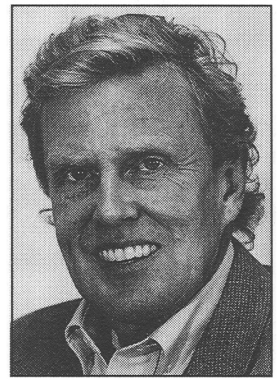

The fat content of the foetus of $1000 \mathrm{~g}$ increases from only $1 \%$ to $15-17 \%$ at term, corresponding to an energy reserve of approximately 5000 Kcal. Carbohydrates are stored in the last weeks of gestation as glycogen to a very limited extent. This reserve, less than $5 \%$ of the body weight, is rapidly depleted, explaining why an infant is very prone to develop hypoglycaemia during fasting. The protein accretion rate is relatively constant throughout gestation in contrast to fat accretion. Using Widdowson's data one can assume that the foetus at 24 weeks of gestation has a protein content of $25 \mathrm{~g}$ and at term $250 \mathrm{~g}$ (5). All these data are somewhat unreliable and correspond only to appropriate for gestational age (AGA) infants. However, without doubt the energy reserves are very limited in neonates. Heird et al. have estimated that a neonate of $1000 \mathrm{~g}$ has only four days of nutritional reserve as compared to 28 days in a term infant (6). Starvation will particularly affect certain some organs, i.e. the brain, liver, heart and the intestine. The degree of malnutrition in surgical paediatric patients has not been fully documented. Paediatric patients at particular risk of malnutrition are LBW infants and those with sepsis and burns. After an operation it is common practice to prescribe only $10 \%$ glucose for a couple of days up to more than a week. The energy needs are therefore not met (often less than 50\%) and it is obvious that the surgeon/ paediatrician using such a regimen is the cause of malnutrition in the infant.

\section{Renal physiology}

Total body water (TBW) slowly decreases to adult levels of $60 \%$ by one year of age. Extracellular water falls in parallel with TBW from $45 \%$ to $20-25 \%$ by one year of age and is handled by the kidney. Glomerular filtration rate (GFR) of the term infant is approximately $20-25 \mathrm{ml} /$ $\mathrm{min} / 1.73 \mathrm{~m}^{2}$ corresponding to approximately $1 / 4$ of adult values. The GFR increases rapidly during the first postnatal week and is similar to adult values at two years of age. However, infants can handle a high water load despite a low GFR due to the effect of low concentrating capacity. Dehydrated newborns have less capacity to concentrate urine. It is important before an operation to evaluate any disturbances in body fluid and to compensate for any deficit which has occurred. This may be estimated from a patient's history, condition and blood chemistry. Patients with hypertonic dehydration (serum osmolarity $>310$ and serum $\mathrm{Na}>150$ ) must be identified before the operation due to the risk of CNS complications. Isotonic and hypotonic dehydration must also be compensated before the operation with isotonic fluid. Fluid therapy should also cover normal and abnormal fluid electrolyte losses, e.g. by an ileostomy which sometimes may be difficult to estimate.

\section{Nutritional assessment}

It is essential to try to evaluate the nutritional status before and after operation. The assessment can be divided into two parts: a subjective and objective part. The subjective valuations are based on the patient's history and physical examination.

The maturity, gestational age, potential oedema and level of dehydration must be determined. Anthropometric measurements, i.e. body weight in relation to gestational age, length and head circumference plotted on a growth curve are valuable indices of any disturbances. The weight for height index may be calculated, 
which is an indicator of acute malnutrition $(7,8)$. Length is a good indicator of skeletal growth. The triceps skinfold thickness, which correlates with total body fat store, can be measured by a caliper. Mid arm muscle circumference, which correlates to muscle mass, is a valuable indicator of the patient's nutritional status but seldom used by the physician (9).

The biochemical measurements of nutritional status which can be used are albumin, pre-albumin, retinol binding protein, transferrin and collagen 1-c and somatomedin-C. Measurements of serum albumin levels can be useful, but the halflife is 20 days and the levels can be altered by disturbances of hepatic synthesis, redistribution in the plasma space and hydration of the infant, thus not reflecting acute changes in the nutritional status. However, hypoalbuminaemia is associated with increased morbidity and mortality rates (10). Pre-albumin binding protein has a short half-life (2 days) and might be a better indicator than albumin of acute changes in nutritional status.

Retinol binding protein has a very short half-life (12 hours) and is also marker of nutritional status. Transferrin, a transport glycoprotein, has a half-life of 8.8 days and the body pool of transferrin is smaller than albumin, which makes it valuable to monitor. Parameters of immune function are influenced by the nutritional status (11). The amount and function of lymphocytes can be altered. The delayed hypersensivity skin tests and immune competence can be partly measured by the lymphocyte count and skin test reactivity in a chronically malnourished infant.

The hepatic synthesis of acute phase proteins is increased during the postoperative days (18). This is mediated by cytokines, which will favour synthesis of acute phase proteins at the expense of synthesis of visceral proteins (19). C-reactive protein (CRP) reaches peak levels 1-2 days after injury or operation. Serial measurements of CRP, pre-albumin and energy expenditure during the perioperative period in infants have shown significant differences between survivors and non-survivors, indicating that monitoring of these values can early give hints of postoperative complications (20). A similar study in infants with postoperative infective complications showed that a rise in CRP and pre-albumin occurred earlier than a rise in body temperature or leukocyte count (21).

\section{Energy requirements}

Newborn infants have a higher metabolic rate and energy requirement per $\mathrm{kg}$ body weight than children and adults (12).
Infants receiving total parenteral nutrition (TPN) require less energy due to lower energy losses by the alimentary tract. Resting energy expenditure (REE) is increased in severely injured adults and during the first postoperative days (13). The hypermetabolic state is mediated by a neuroendocrine stress response, which stimulates gluconeogenesis, protein catabolism and fat oxidation. In newborn infants there seems to be no substantial increase in REE except for the first 6 postoperative hours (14-16). On the other hand, older neonates and infants had an apparent increase of REE. It is possible that postoperative infusion of opioids for pain relief may inhibit this increase. Postoperative increase in REE can also be caused by sepsis or other postoperative complications. It has also been shown that neonates after surgery have a decreased amount of gluconeogenesis.

Energy expenditure for growth is also diminished. Studies have also shown that infants do not have any increase in whole body protein turnover after surgery, indicating a change of protein synthesis from growth to tissue repair (17). There is thus a limited risk of overfeeding neonates after an operation, which may lead to fluid retention and respiratory and cardiac complications.

\section{Preoperative care}

When a congenital abdominal malformation is suspected it is mandatory that the neonate has a gastric tube and an intravenous line inserted preoperatively. Analysis of acid-base, haemoglobin, glucose, renal and liver function, electrolytes, thrombocytes, CRP, International Normalized Ratio (INR), triglycerides and prealbumin should be estimated. Five to ten per cent dextrose should be given at a rate which will compensate for earlier losses, ongoing losses and the daily fluid requirement. Sodium but not potassium should be added. Any disturbances in acidbase must be corrected before operation.

All investigations, i.e. X-ray, should be performed in a thermo-neutral environment. There is no study on neonates which shows that preoperative compensation of nutritional losses reduces the postoperative complication rate, but one feels clinical experience suggests that this is the case.

\section{General anesthesia}

Newborn infants with a greater ratio of body surface/body weight have difficulties in maintaining their body temperature in a cold environment (22). They are unable to respond by shivering, but the brown fat can partly counteract by heat production. Hypothermia is associated with an increase in postoperative complications. It is of utmost importance that the operating theatre is warm $\left(25-32^{\circ} \mathrm{C}\right)$ and the infant is covered, breathing gases and receiving infusion solutions are thermoneutral.

However, during surgery newborn infants seem to decrease metabolic rate and maintain a stable body temperature as a sign of protective survival mechanism (23).

\section{Parenteral nutrition requirements}

Protein: The protein requirement is high during the first year of life. There are at least 8 amino acids which are essential, but more evidence shows that for neonates at least another 4 to 7 are semiessential due to immature amino acid synthetic pathways. These are histidin, cystein, taurine, tyrosine, prolin and glutamine and arginine $(24,25)$. Glutamine is the most abundant amino acid in the body and is an important precursor for nucleic acid biosynthesis, i.e. for cells which rapidly turnover such as the enterocytes in the intestinal mucosa (26). Only amino acids solutions designed for neonates and infants should be used. These solutions have an amino acid profile which, in studies, do not seem to change the plasma aminogram of the neonates as much as solutions designed for adults. Studies have also shown that higher nitrogen retention is seen in neonates infused with a lower amino acid amount (27). In neonates it is recommended to start with $0.5-1 \mathrm{~g} / \mathrm{kg}$ of amino acids and in infants $1.0-1.25 \mathrm{~g} / \mathrm{kg} / \mathrm{day}$.

Fat: Fat has a high energy density of 9 $\mathrm{Kcal} / \mathrm{g}$ and is required as a source for the essential fatty acids linoleic and linolenic acid. Linolenic acid is probably essential for the development of the brain of the neonate. However, too much linolenic acid inhibits the conversion of linolenic to aracidonic acids. Deficiency of the essential fatty acids may occur rapidly in the newborn infant. Chemical signs are seen only 2 days after a nonlipid infusion (28). Two to four per cent of the total energy should come from these fatty acids. Essential fatty acid deficiency is considered if the ratio of 5.8-11 eicosatreienoic to aracidonic (triene to tetraene) is greater than 0.4 . The contribution of fat should not exceed $50 \%$ of total nonnitrogen energy but rather $30-40 \%$. LBW infants and especially those who are extremely preterm have a lesser capacity than term infants to clear fat from the bloodstream and therefore lipid infusion should not exceed $4 \mathrm{~g} / \mathrm{kg} / 24 \mathrm{~h}$ for term infants and $2-3 \mathrm{~g} / \mathrm{kg} / 24 \mathrm{~h}$ for LBW infants and preterm infants below $1000 \mathrm{~g}$. Lipid infusions should be infused over $24 \mathrm{~h}$. This 
Table 1. Infusion of $20 \%$ intravenous fat emulsion $\mathrm{g} / \mathrm{kg} / \mathrm{day}(\mathrm{ml} / \mathrm{kg} / \mathrm{day})$.

Premterm Fullterm Infants and neonates SGA inf

\begin{tabular}{llll}
\hline Initial dose & $0.5(2.5)$ & $1(5)$ & $2(10)$ \\
Daily increase & $0.5(2.5)$ & $1(5)$ & $1(5)$ \\
Maximum dose & $3(15)$ & $4(20)$ & $4(20)$
\end{tabular}

Table 2. Amino acid requirements.

\begin{tabular}{lc}
\hline Age group & $\begin{array}{c}\text { Amino acids } \\
\mathrm{g} / \mathrm{kg} / \text { day }\end{array}$ \\
\hline Preterm neonates & $2.5-3.0$ \\
Fullterm neonates, infants & $2.0-2.5$
\end{tabular}

Table 3. Basal requirements of some minerals after the 3d postnatal day.

$\mathrm{mmol} / \mathrm{kg} / 24 \mathrm{~h}$

\begin{tabular}{ll}
\hline Sodium & $2.0-3.0$ \\
Potassium & $2.5-3.5$ \\
Chloride & $2.0-3.0$ \\
Acetate & $1.0-4.0$ \\
Magnesium & $0.1-0.3$ \\
Calcium (gluconate) & $1.0-2.0(-4.0$ Preterm) \\
Phosphate & $0.25-1.6$
\end{tabular}

is particulararly the case when fat is given to LBW infants. Cyclic infusion $(12 \mathrm{~h}$ infusion) will exceed the highest recommended infusion $0.15 \mathrm{~g} / \mathrm{kg} / \mathrm{h}$ if enough lipids are to be given during the day.

For a longer period of time ( more than a month) it is advisable to include carnitine, which is necessary for $\beta$-oxidation metabolism of the long-chain fatty acids. Infants on long-term parenteral nutrition not receiving carnitine have low plasma carnitine levels. Infants receiving carnitine $(50 \mu \mathrm{mol} / \mathrm{kg} /$ day $)$ seem to tolerate the fat better.

Fat emulsion containing a mixture between long-chain and medium-chain (MCT) fatty acids have been used to a limited extent on neonates and infants. MCT does not need carnitin for $\beta$-oxidation and is not stored in the liver or adipose tissue.

There are some indications that longterm use of soybean-based fat emulsion, which has no eicosapentaenoic (EFA), or docosahexaenoic (DHA) and high levels of linolenic acid, does not support the development of the neonatal brain. It has also been shown that high levels of linolenic inhibit conversion to EPA and DHA.
It is recommended to use $20 \%$ fat emulsion. Since this emulsion also has glycerol and phospholipids it will generate $2 \mathrm{kcal}$ per $\mathrm{ml}$ emulsion. It has a favourable phospholipid/triglyceride ratio of 0.06 compared to 0.12 for $10 \%$ fat emulsion. Phospholipid is believed to inhibit lipoprotein lipase, which is the most active enzyme for fat emulsion.

\section{Postoperative care}

Most neonates and infants undergoing major surgery do not tolerate enteral feeding in the first postoperative days. It is therefore recommended to start with a complete programme of parenteral nutrition. It is not advisable to give only dextrose for a couple of days as the infant is deprived not only the energy needed but also many essential nutrients. As complete as possible parenteral nutrition programme should be given. Even if no bowel movements are noticed, a few $\mathrm{ml}$ of breast milk should be given to promote secretion of gut hormones, support the enterohepatic circulation and initiate peristalsis of the bowel.

Dextrose: If a peripheral line is used concentrations higher than $10 \%$ dextrose should not be used, particicularly in LBW infants. When central lines are used, $10 \%$ dextrose should be used initially and then the concentration can be increased to $15 \%$ or $20 \%$ if the energy requirement is high. As the water requirement is to a great extent covered by the dextrose solution, care must be taken not to infuse excess water. Excessive fluid in the LBW infant may be associated with complications like a patent ductus arteriosus, necrotising enterocolitis and broncopulmonary dysplasia.

Fat: The lipid infusion is started the day after operation and gradually increased Table 1.

Protein: The maximum infusion is shown in Table 2 with a start of $0.5-1 \mathrm{~g} / \mathrm{kg} / 24 \mathrm{~h}$ for neonates and $1.0-1.25 \mathrm{~g} / \mathrm{kg} / 24 \mathrm{~h}$ for infants. Water requirement: Fluid is given according to the calculated need.

Minerals and fat and water soluble vitamins: Minerals including trace elements, fat and water-soluble vitamins should be put in the parenteral nutrition programme directly. A guideline for recommendations for some minerals is shown in Table 3. Calcium and phosphate requirements for $\mathrm{LBW}$ infants sometimes exceed their solubility in PN solutions depending on the $\mathrm{pH}$ of the individual solution. The exact requirement of minerals, especially trace minerals and vitamins are not fully established but using commercially available solutions will probably cover the requirement for a short period of time. When TPN is used for a longer period this may not be adequate.

\section{Route of administration}

Peripheral lines may be used for several days up to several weeks, but when it is likely that parenteral nutrition will be needed for more than a week (e.g. gastroschisis, volvulus-intestinal resections) it is advisable to insert a central line by the jugular vein with the tip of the line placed in the lower part of the superior caval vein or in the right atrium. The position of the line should be confirmed by X-ray.

\section{Monitoring}

Laboratory monitoring is particularly mandatory in the first days of TPN. In addition to laboratory monitoring daily weight and respiratory and cardiac frequencies should be monitored. When TPN is started, analyses of acid base, haemoglobin, glucose, electrolytes, thrombocytes, triglycerides should be performed at least once a day and renal function, liver function and INR at least once a week. When the patient is stable these values can be estimated less frequently. Urine output should be analysed for glucose, albumin and electrolytes.

\section{Complications}

Nowadays metabolic complications seldom appear when a balanced parenteral nutrition programme is used for up to $2-3$ weeks. After that period of time, use of parenteral nutrition without any enteral feeding is often associated with liver dysfunction (choleastasis), particularly in LBW infants. It is thus of the utmost importance to give a few $\mathrm{ml}$ of breast milk by the enteral route even if the bowel is not functioning. Electrolyte and glucose imbalances are often seen and must be corrected. Hypertriglyceridaemia is rarely seen when the lipid infusion does not exceed recommendations.

Sepsis secondary to central lines is not uncommon. It may be caused by improper care of the catheter or translocation of bacterias from the intestine. The line can still be used in bacterial sepsis, but the line must be withdrawn when fungal sepsis occurs.

\section{Antibiotics}

It is mandatory to give prophylactic antibiotics to neonates just before operation and normally continue them for at least 2 7 days. This will reduce the incidence of sepsis. The antibiotics frequently used are cephalosporins, aminoglycosides and imidazol. 


\section{Enteral feeding}

The enteral route should be used as soon as possible or rather before! A few $\mathrm{ml}$ of breast milk can be given before the bowel starts to function. Parenteral nutrition should gradually be decreased and the dextrose infusion can be reduced faster than the amino acid and the fat emulsion infusion. For neonates breast milk is preferred. Feeds can initially be commenced in small bolus volumes $(1.0-5 \mathrm{ml})$ every 2-3 hours and increased gradually. Sometimes it is necessary to give the

\section{REFERENCES}

1. Chwals WJ: The newborn as a surgical patient. Metabolic considerations. In Pediatric Surgery, edn 5. Edited by O'Neill JA, Rowe MI, Grosfeld JL, Fonkalsrud EW, Coran AG. St. Louis, MO Mosby-Year Book;1998;57-70.

2. Teitelbaum DH, Coran AG: Perioperative nutritional support in pediatrics. Nutrition 1998 14:130-42.

3. Velasco AL, Ziegler MM: The nutritional management of the ill child. In: McLaren DS, Burman D, Belton NR, Williams AF (eds) Textbook of paediatric nutrition. Churchill Livingstone, Edinburgh 1991;269-79.

4. Heim T: Energy and lipid requirements of the foetus and the preterm infant. JPGEN 1983;2: $16-41$.

5. Widdowson EM: Growth and composition of the foetus and neonate. In: Assali NS (ed) Biology of gestation, vol 2. The foetus and neonate. Academic Press, New York.1969;1-49.

6. Heird W, Driscoll J, Schullinger J: Intravenous alimentation in pediatric patients. J Pediatr 1972;80:351-4.

7. Waterlow JC: Classification and definition of proteincalorie malnutrition, Br Med J 1972; 3:566-9.

8. Waterlow JC: Note on the assessment and classification malnutrition in children, Lancet 1973;2:87-9.

9. Chiba T, Lloyd DA, Bowen AD et al: Ultrasonography as a method of nutritional assessment. JPGEN 1989;13:529-34.

10. Kenny SE, Pierro A, Isherwood D et al: Hypo- breast milk continuously $(1-2 \mathrm{ml} / \mathrm{h})$ by pump when bolus feeding is not tolerated. It is believed that a gastric tube may paralyse the stomach. The amount of enteral feeding depends on the residual gastric volumes, stool frequency, all of which must be recorded daily.

Sometimes it is helpful to stimulate the rectum or to give an enema. Daily recording of the weight of the neonate is mandatory.

In some situations a mixture of breast milk and formula can be used.

albuminaemia in surgical neonates receiving parenteral nutrition. J Pediatr Surg 1995; 30:454-7.

11. Neumann CG et al: Immunological response in malnourished children. Am J Clin Nutr 1975; 28:89-104.

12. Brooke OG: Energy expenditure in the foetus and neonate: sources of variability. Acta Paediatr Scand Suppl 1985;319:128-34

13. Long CL, Schaffel N, Geiger JW et al: Metabolic response to injury and illness: estimation of energy and protein needs from indirect calorimetry and nitrogen balance. JPGEN 1979;3:452-6.

14. Shanbhogue RLK, Jackson M, Lloyd DA: Operation does not increase resting energy expenditure in the neonate. J Pediatr Surg 1991; 26:578-80.

15. Pierro A, Carnielle V, Filler RM et al: Partition of energy metabolism in the surgical newborn. J Pediatr Surg 1991;26:581-6.

16. Jones MO, Pierro A, Hammond P, Lloyd DA: The metabolic response to operative stress in infants. J Pediatr Surg 1993; 28:1258-63.

17. Powis M, Smith K, Rennie M et al: Effect of major abdominal operations on energy and protein metabolism in infants and children. $\mathrm{J}$ Pediatr Surg 1998;33:49-53.

18. Ohzato $\mathrm{H}$, Yoshizaki $\mathrm{K}$, Nishimoto $\mathrm{N}$ et al: Interleukin-6 as a new indicator of inflammatory status: Detection of serum levels of interleukin-6 and C-reactive protein after surgery. Surgery 1992;111:201-9.

19. Dickson PW, Bannister D, Schreiber G: Minor

\section{Home parenteral nutrition}

Home parenteral nutrition can be used in infants, but this will not be discussed here.

\section{Conclusion}

The perioperative care of neonates, especially preterm infants, is a great challenge for the paediatric surgeon. Due to improvements of respiratory care, new antibiotics, parenteral and enteral formulas and not least a better knowledge of the metabolic requirement, these infants can survive and obtain a good quality of life.

burns lead to major changes in synthesis rates of plasma proteins in the liver. J Trauma 1987; 27:283-6.

20. Chwals WJ: The metabolic response to surgery in neonates. Clin Opin Pediatr 1994; 6:334-40.

21. Chwals WJ, Fernandez ME, Jamie AC et al: Detection of postoperative sepsis in infants with the use of metabolic stress monitoring.Arch Surg 1994;129:437-42.

22. OkadaY, Powis M, MCEwan A et al: Fentanyl analgesia modulates the thermogenic response in neonates undergoing major operations. Pediatr Surg Int 1998;13:508-11.

23. Coran AG, Pierro A, Schmeling DJ: Metabolism of the neonate requiring surgery. In Principles of Perinatal-Neonatal Metabolism, edn 2. Edited by Cowett RM. New York: Springer; 1998:1131-51.

24. Laidlaw SA, Kopple JD: Newer concepts of the indispensable amino acids. Am J Clin Nutr 1987;46:593-605.

25. Jackson A: Optimizing amino acid and protein supply and utilization in the newborn, Proc Nutr Soc 1989;48:293-301.

26. Ardawi MSM, Newsholme EA: Glutamine, the immune system and the intestine, J Lab Clin Med 1990;115:654-5.

27. Helms RA: Altered caloric and protein requirement in neonates receiving a pediatric amino acid formulation. Pediatr Res 1987; 21:429A.

28. Friedman Z, Danon A, Stahlman MT et al: Rapid onset of essential fatty acid deficiency in the newborn. Pediatrics 1976;58:640-5. 